\title{
Investigation of TASS/SMR Capability to Predict a Natural Circulation in the Test Facility for an Integral Reactor
}

\author{
Young-Jong Chung, Sung-Won Lim, and Kyoo-Hwan Bae \\ Korea Atomic Energy Research Institute, 989-111 Daedeok-daero, Yuseong-gu, Daejon 305-353, Republic of Korea \\ Correspondence should be addressed to Young-Jong Chung; chung@kaeri.re.kr
}

Received 11 April 2014; Revised 13 June 2014; Accepted 17 June 2014; Published 21 August 2014

Academic Editor: Giorgio Galassi

Copyright ( 2014 Young-Jong Chung et al. This is an open access article distributed under the Creative Commons Attribution License, which permits unrestricted use, distribution, and reproduction in any medium, provided the original work is properly cited.

\begin{abstract}
System-integrated modular advanced reactor (SMART) is a small-sized advanced integral type pressurized water reactor (PWR) with a rated thermal power of $330 \mathrm{MW}$. It can produce $100 \mathrm{MW}$ of electricity or $90 \mathrm{MW}$ of electricity and 40,000 ton of desalinated water concurrently, which is sufficient for 100,000 residents. The design features contributing to safety enhancement are basically inherent safety improvement and passive safety features. TASS/SMR code was developed for an analysis of design based events and accidents in an integral type reactor reflecting the characteristics of the SMART design. The main purpose of the code is to analyze all relevant phenomena and processes. The code should be validated using experimental data in order to confirm prediction capability. TASS/SMR predicts well the overall thermal-hydraulic behavior under various natural circulation conditions at the experimental test facility for an integral reactor. A pressure loss should be provided a function of Reynolds number at low velocity conditions in order to simulate the mass flow rate well under natural circulations.
\end{abstract}

\section{Introduction}

Many countries have recently taken an interest in small and medium sized reactors. These reactors are considered to be a suitable option for nuclear system deployment in developing countries and nonelectrical applications for various facilities [1]. Korea Atomic Energy Research Institute (KAERI) developed system-integrated modular advanced reactor (SMART) for exporting to countries with small electric grids and water supply issues [2]. SMART, which adopts a sensible mixture of new innovative design features and proven technologies, is a small-sized advanced integral type PWR (pressurized water reactor) with a rated thermal power of $330 \mathrm{MW}$. It can produce $100 \mathrm{MW}$ of electricity, or $90 \mathrm{MW}$ of electricity and 40,000 ton of desalinated water concurrently, which is sufficient for 100,000 residents. Figure 1 shows the schematic diagram of SMART reactor vessel assembly. The design features contributing to safety enhancement are basically passive safety features. The major engineered safety systems function passively using the passive residual heat removal systems (PRHRS). The passive residual heat removal systems remove the core decay heat through natural circulation at any design basis events and have the capability of keeping the core undamaged for 72 hours without any corrective actions by operators.

Advanced design features implemented into SMART should be proven or qualified through experience, testing, or analysis according to the applicable approved standards. TASS/SMR code, which is a system analysis code, has been developed for an analysis of design-based events and accidents in an integral type reactor reflecting the characteristics of the SMART design [3]. In order to apply system analyses of SMART, the code should be validated for all relevant phenomena including a natural circulation that may occur in both a reactor coolant system and a passive residual heat removal system. Most experimental data are produced to find natural circulation characteristics for loop type reactors. The natural circulation flow rate is strongly dependent on the liquid inventory or system void and is weakly dependent on the power level [4]. The natural circulation phenomena and flow rate are predictable for the range of PWR conditions relevant to small breaks and transients. The model can be used to derive simple operating maps that will help the operator identify modes of heat removal during abnormal 


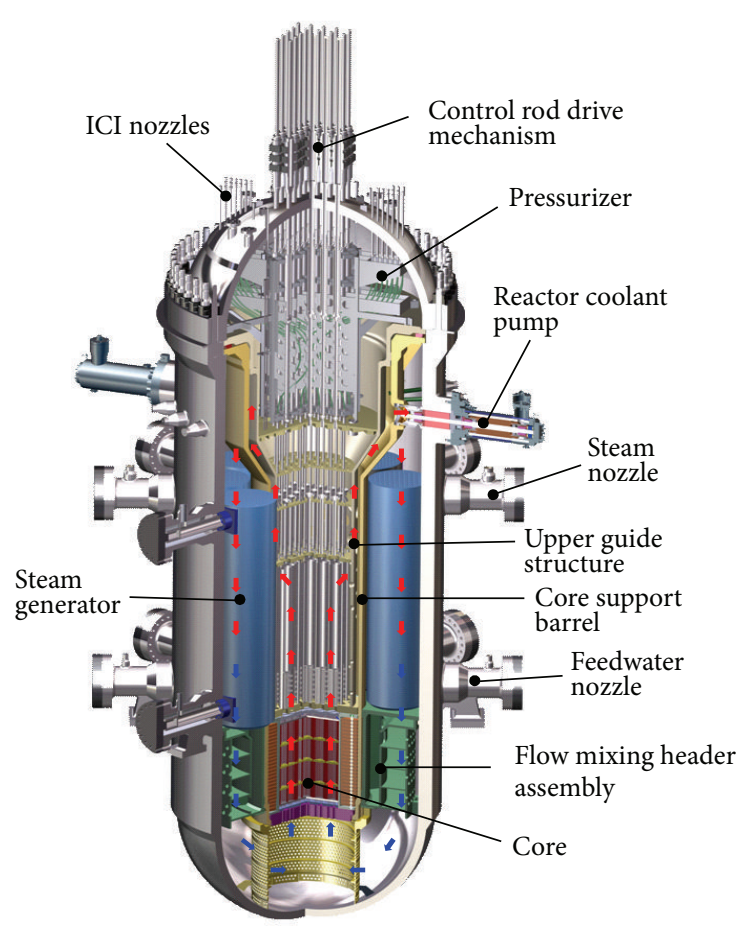

FIGURE 1: SMART reactor vessel assembly.

shutdown conditions. The stability of single-phase natural circulation flows has been studied. The stability parameters were evaluated for the natural circulation tests conducted with the LSTF (large scale test facility) which is an integral test facility for a loop type PWR [5]. It was shown that the normal flows in shorter $\mathrm{U}$ tubes were found to become stable if the flows in several longer $U$ tubes were stalled under the unstable condition. The importance of an appropriate operating regime was proposed especially for SMRs with passive systems having a natural circulation loop [6]. In addition, the capability of the system code to simulate natural circulation behavior in the test facilities was validated for various conditions [7]. Many investigations for natural circulation characteristics with a loop type PWR or test facility were performed over the past several decades and the system codes were validated using those data. However, validation work as well as experimental data are lacking for integral type facilities and reactors. The main objective of this study is to validate the capability of TASS/SMR code to predict the overall thermal-hydraulic behaviors under various natural circulation conditions for an experimental facility, OSU-MASLWR, which is an integral test facility for simulation of an integral type reactor MASLWR. The secondary objective is to investigate the characteristics of natural circulation phenomena.

\section{Experimental Facility and Analysis Code: TASS/SMR}

2.1. OSU-MASLWR Experimental Facility. MASLWR is a system-integrated pressurized light water reactor. All the

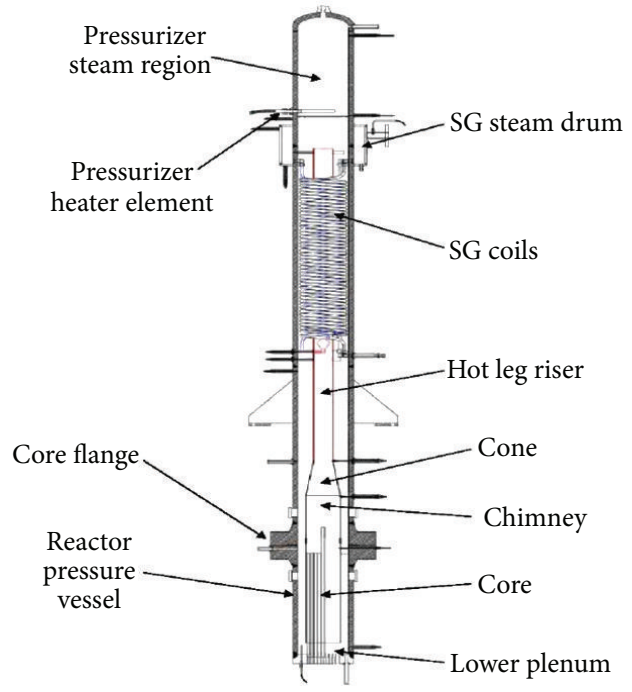

FIGURE 2: Layout of reactor pressure vessel: OSU-MASLWR facility.

primary system components are housed within a pressure vessel. The pressure vessel of MASLWR is surrounded by the high pressure containment (HPC) vessel which is partially filled with water. The containment vessel provides primary system suppression capability as well as core makeup capability using an automatic depressurization system (ADS). These safety systems of MASLWR are operated passively. The water in the cooling pool vessel (CPV) is an ultimate heat sink that removes the decay and residual heat of the reactor system. The primary flow inside the vessel is driven by natural circulation during normal and transient operations. The OSU-MASLWR facility was constructed to model the conceptual design of the MASLWR [8]. Major components of MASLWR were modeled at the test facility, as shown in Figure 2 . The test facility was scaled at 1:3 for length, $1: 254$ for volume, and $1: 1$ for time and was modeled for full pressure of $11.4 \mathrm{MPa}$ and temperature of $590 \mathrm{~K}$. The test facility includes three major components. The first is the primary coolant system which includes the reactor pressure vessel with its internal components such as core, hot leg riser, steam generators, and pressurizer. The second is the secondary system which includes the steam generator secondary side, feedwater pump, and associated feedwater and steam valves. The third is the containment structure.

A test was performed to characterize the steady-state natural circulation in the primary side during various core power levels. The power inputs of the core heaters were increased step by step from 10 percent to 80 percent of full power. The ambient temperature during the test was estimated to be 293 297 K [9].

2.2. Analysis Code: TASS/SMR. TASS/SMR code has been developed for an analysis of design based transients and accidents in an integral type reactor reflecting the characteristics of the SMART design. The main purpose of the code is to simulate all relevant phenomena, processes, and conditions of a reactor coolant system that may occur, and several 
TABLE 1: Initial conditions for natural circulation test.

\begin{tabular}{lcc}
\hline Parameter & Experiment & Calculation \\
\hline PZR pressure, MPa & 8.72 & 8.72 \\
PZR level, $\mathrm{m}$ & 0.36 & 0.36 \\
Power, $\mathrm{kW}$ & $41.05^{*}$ & $41.1^{*}$ \\
Core inlet temperature, K & 523.49 & 523.97 \\
Core outlet temperature, K & 535.87 & 535.92 \\
Primary flow rate, kg/s & $(0.50)$ & 0.67 \\
Feedwater temperature, K & 304.64 & 304.74 \\
Steam temperature, K & 529.09 & 534.58 \\
Steam pressure, MPa & 1.46 & 1.46 \\
Feedwater flow rate, $\mathrm{kg} / \mathrm{s}$ & $0.0103^{*}$ & $0.0101^{*}$ \\
\hline
\end{tabular}

${ }^{*}$ Represents boundary condition.

conservative transient models were adopted in the code to describe the thermal-hydraulic behaviors of the plant. An analysis with TASS/SMR code is based on system modeling which consists of node and path. A node is a control volume that has mass and energy, and each node is connected by a path. Nodes can consist of water, steam, and noncondensable gas, and their thermal-hydraulic behaviors are calculated with 3 HEM (homogeneous equilibrium model) equations having drift-flux model [10]. The drift-flux model makes up for the weak point in the 3-equation HEM model. First, verification of the code is performed to assess the software correctness and numerical accuracy of the solution. Then, computational models based on comparisons between computational simulations and experimental data are assessed. Validation is performed using existing international data as well as SMART specific experimental data according to PIRT (phenomena identification and ranking table) results [11].

Figure 3 shows a nodalization of OSU-MASLWR facility. The core and steam generator are modeled by 6 and 10 control volumes with the same height, respectively, and the core power fraction is evenly distributed to each node. Every structure of the primary system, such as the vessel and barrel, and HPC are considered as a heat structure. However, structures for the secondary system, HPC and CPV are not considered as a heat structure except for the heat transfer plate between the HPC and CPV. Ambient heat loss is given as the boundary condition for an analysis and is proportionally distributed by height to the vessel.

\section{Results and Discussion}

The initial conditions are carried out using a pressurizer water level of $0.36 \mathrm{~m}$, a pressurizer pressure of $8.72 \mathrm{MPa}$, and a core heater power of $41.1 \mathrm{~kW}$. The heat loss to the ambient is assumed to be $12.25 \mathrm{~kW}$ from experimental results. TASS/SMR code predicts the initial conditions well, as shown in Table 1. The degree of super steam at the steam generator outlet is predicted to be $64.4 \mathrm{~K}$ which is $5 \mathrm{~K}$ higher than the experiment [11].

The heater power and feedwater flow rate are boundary conditions. The code treats these inputs properly, as shown in Figures 4 and 5. The transient is initiated by an increase

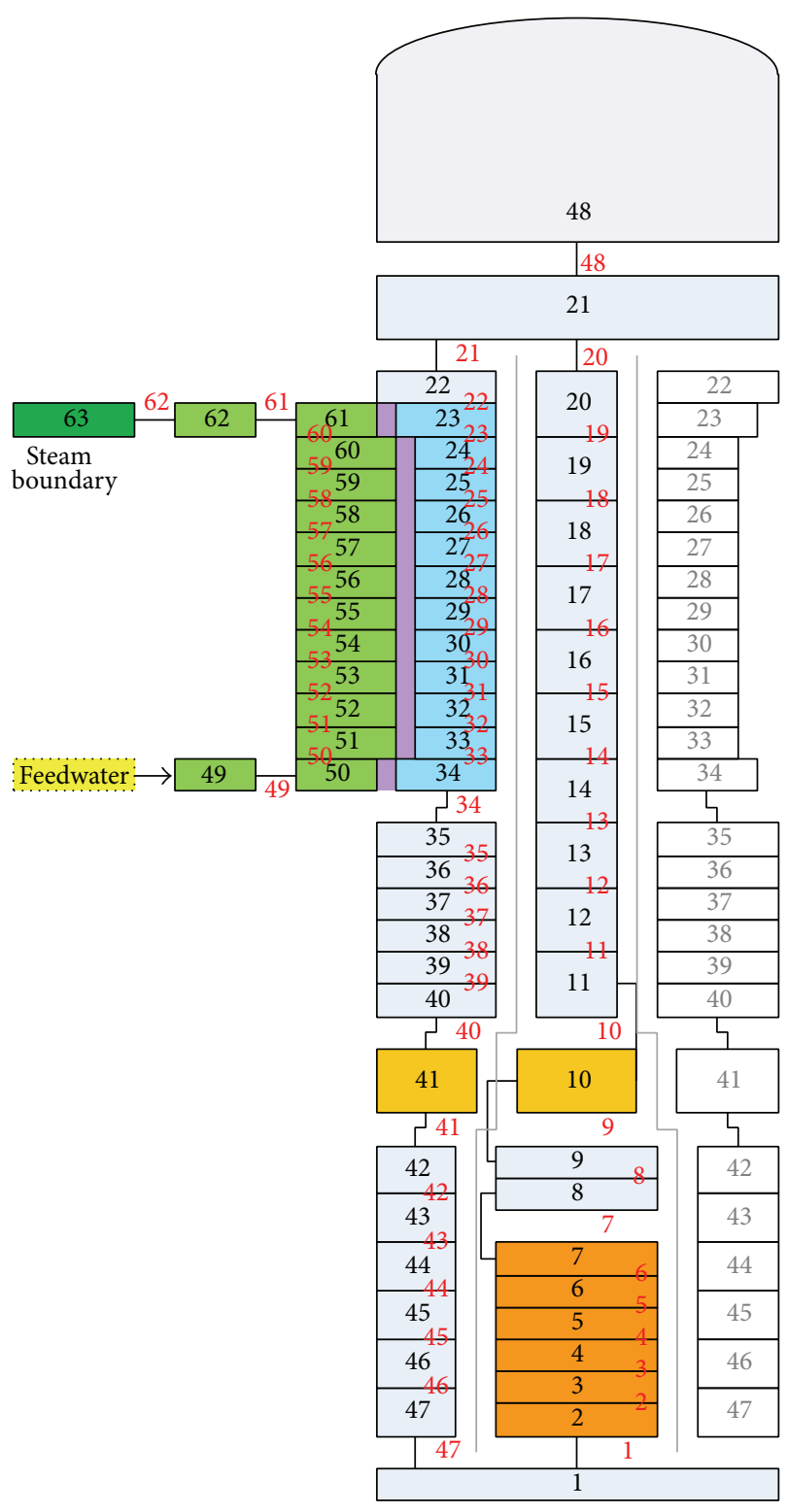

FIGURE 3: Nodalization of OSU-MASLWR facility.

in the heater power step by step. A natural circulation flow is developed as shown in Figure 6 owing to a density difference between heat generation in the core and heat removal through the steam generator. The flow rate increases with the heater power. TASS/SMR code over-predicts the primary natural circulation flow at $40 \mathrm{~kW}$ but the code underpredicts it at $320 \mathrm{~kW}$. The mass flow increases to $1.9 \mathrm{~kg} / \mathrm{s}$ from $0.5 \mathrm{~kg} / \mathrm{s}$ for a power of $320 \mathrm{~kW}$ from $40 \mathrm{~kW}$ in the experiment; however, the code predicts a mass flow rate of $1.48 \mathrm{~kg} / \mathrm{s}$ from $0.67 \mathrm{~kg} / \mathrm{s}$. An increasing ratio of the calculated mass flow is smaller than the experimental results. As a result, the fluid temperature difference between the core inlet and outlet is over-predicted at the end of the transient as shown in Figure 7. A sensitivity study was carried out improving the primary mass flow and fluid temperature. The pressure loss is constant under all flow conditions for 


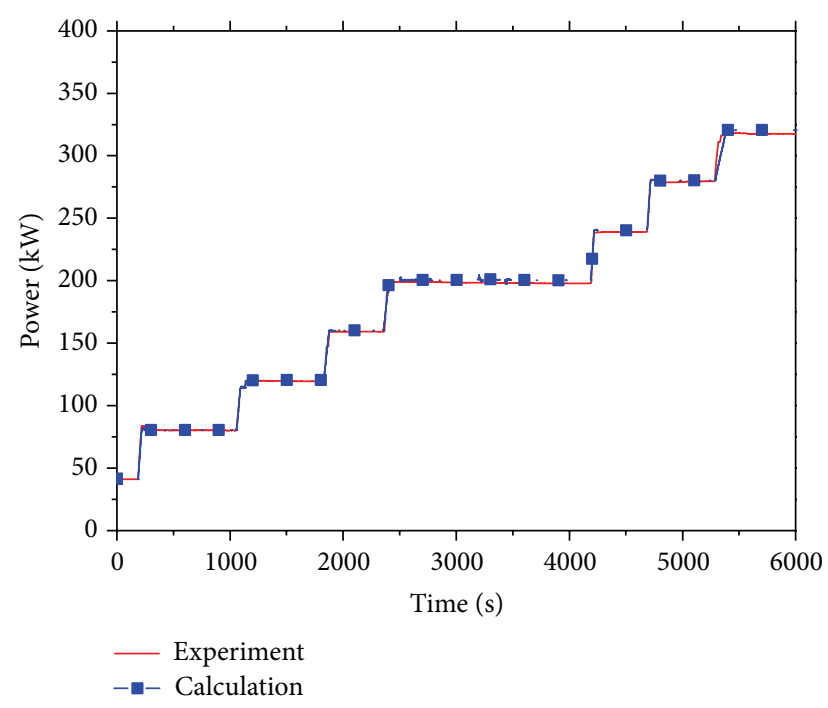

FIgURE 4: Heater power for each step.

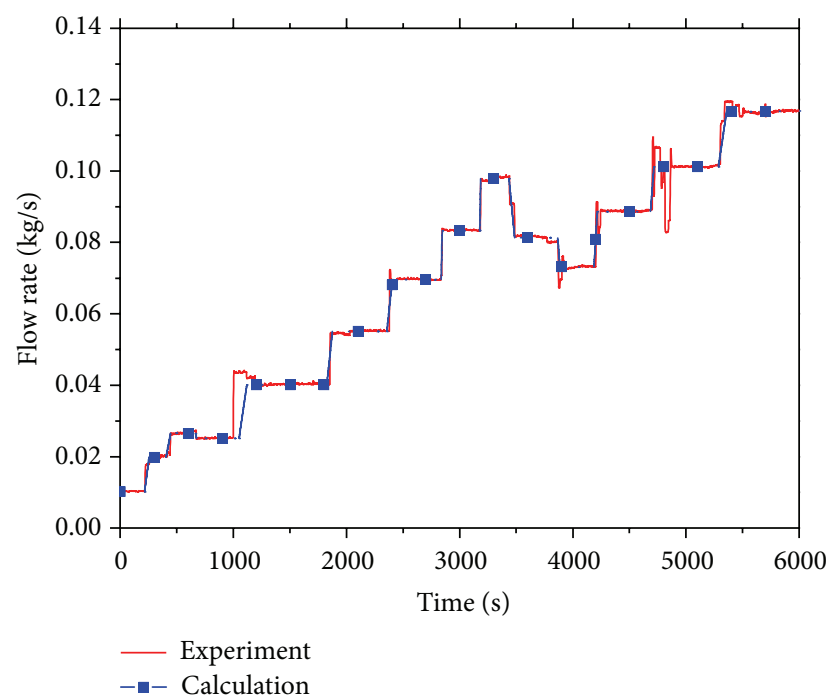

FIgURE 5: Feedwater mass flow rate for each step.

the reference calculation. It is assumed that a pressure loss is a function of the Reynolds number; the pressure loss increases as the Reynolds number decreases. According to this relationship, the primary mass flow and temperature difference are improved for the various power level as shown in Figure 8. It is recommended that the input data to predict a pressure loss well should be provided a function of the Reynolds number under low velocity conditions including natural circulation.

To evaluate the bypass heat transfer between the hot and cold sides in the reactor vessel, the fluid temperatures difference between the hot side and cold side in the pressure vessel are compared in Figure 9. The code under-predicts the temperature difference between the core outlet and the SG inlet slightly. From the temperature difference and coolant flow rate, the bypass heat transfer could be calculated. The

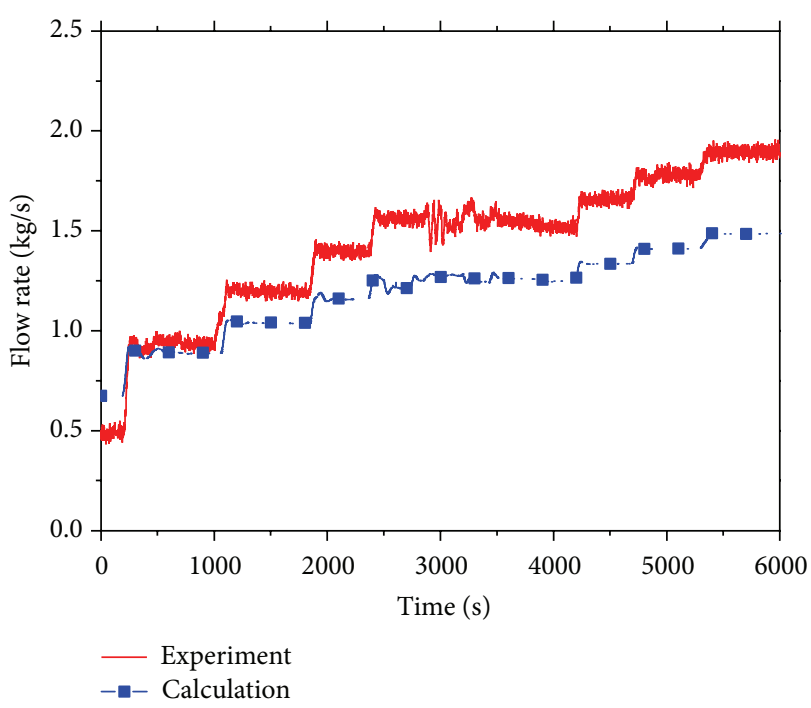

Figure 6: Primary system mass flow rate.

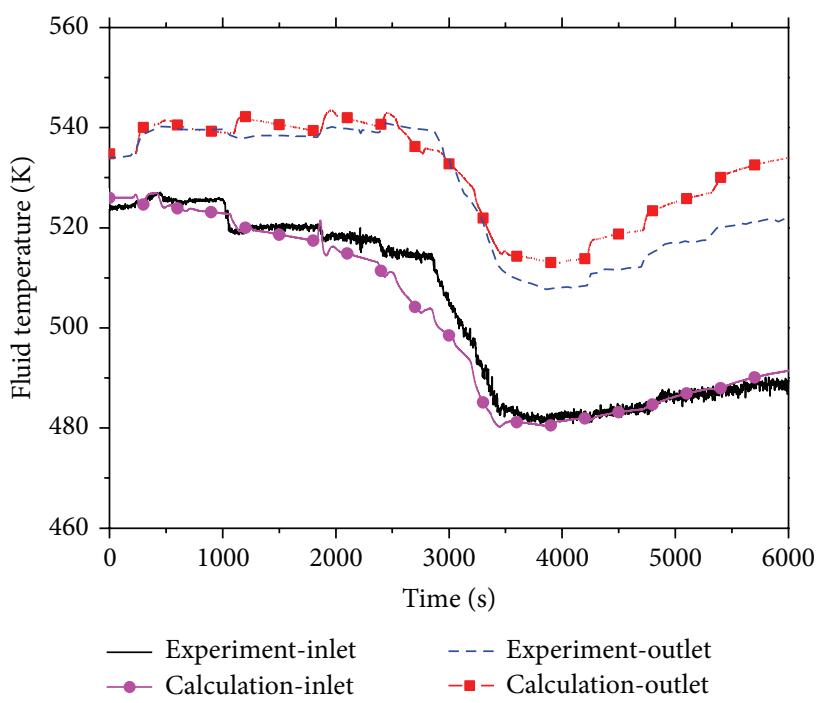

FIGURE 7: Fluid temperatures at the core inlet and outlet.

bypass heat transfer between the core outlet and SG inlet is increased with power, as shown in Figure 10. Figure 11 shows various heat transfers of the primary coolant system. The heat transfer at the steam generator should be equal to the core power minus ambient heat loss when the system keeps a steady state condition. The feedwater flow is supplied more than the required flow to remove the power generated in the core during 2800 3800 seconds, as shown in Figures 5 and 11. As a result of much feedwater supply, the primary coolant temperature decreases (See Figure 7), and the steam temperature reaches a saturation state from super steam as shown in Figure 12. The super steam condition is collapsed at around 3400 seconds owing to much feedwater flow. TASS/SMR code predicts this phenomenon properly at around 3200 seconds. 


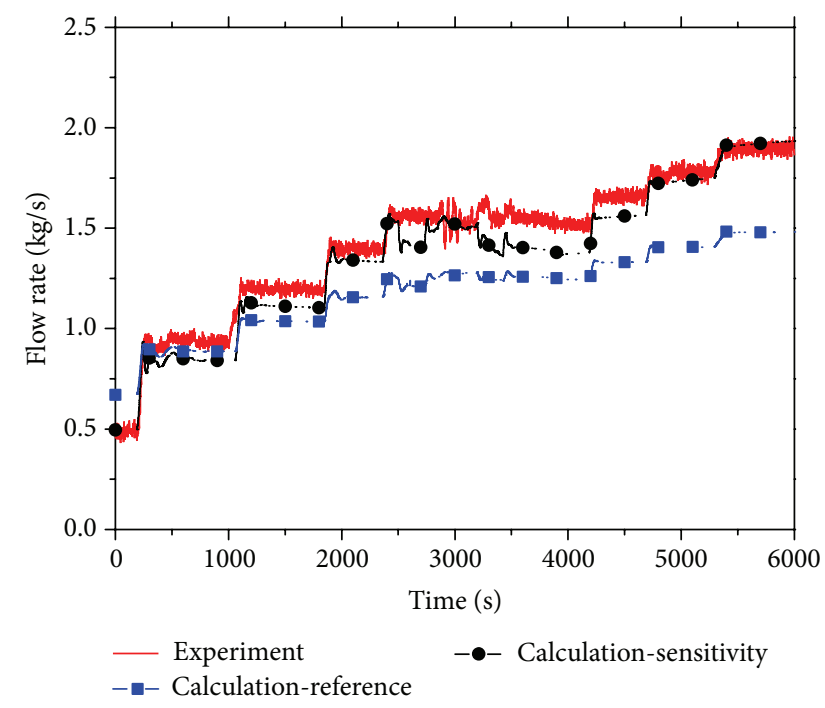

Figure 8: Primary mass flow rate with different press loss model.

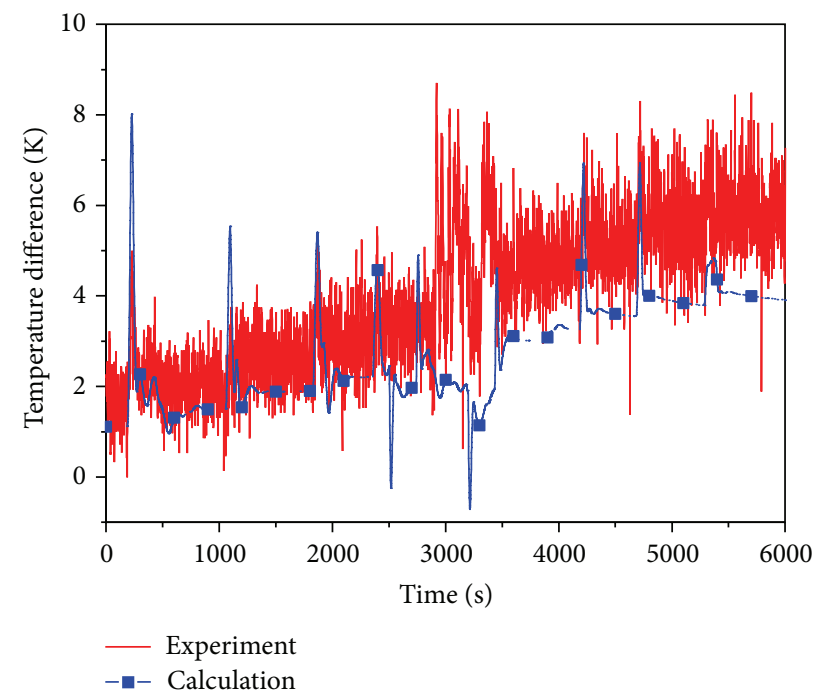

FIgURE 9: Temperature difference between the hot and cold sides.

\section{Conclusion}

The validation work of TASS/SMR code is performed to verify the prediction capability for an integral pressurizer water reactor and improve the understanding of the thermalhydraulic characteristics under natural circulation conditions.

TASS/SMR code predicts the overall behaviors including the system pressure, primary mass flow rate, and fluid temperature under natural circulation conditions for OSUMASLWR facility. It was noticed that a pressure loss should be provided a function of the Reynolds number under low velocity conditions to predict the mass flow rate well including natural circulation. The code can simulate a natural circulation for an integral type reactor having helically coiled steam generator.

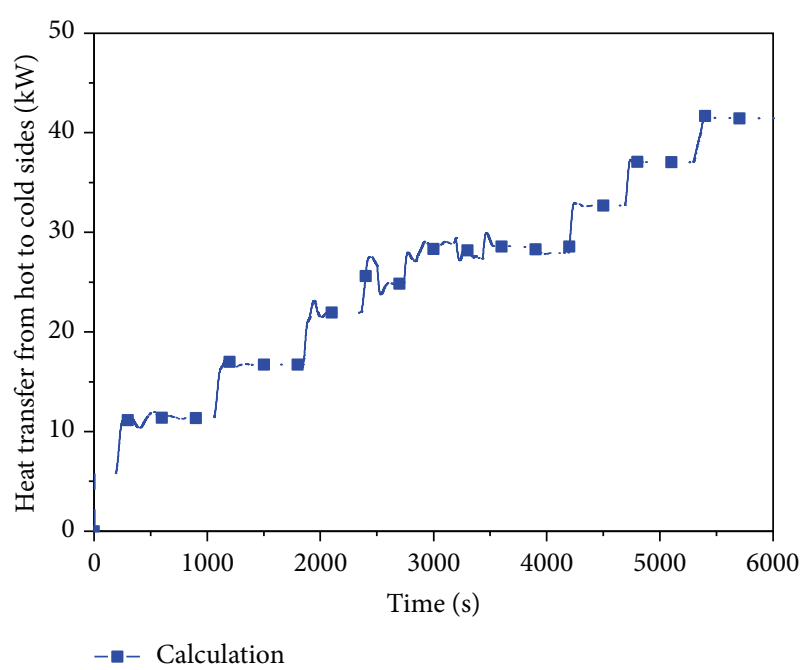

FIgURE 10: Estimated bypass heat transfer.

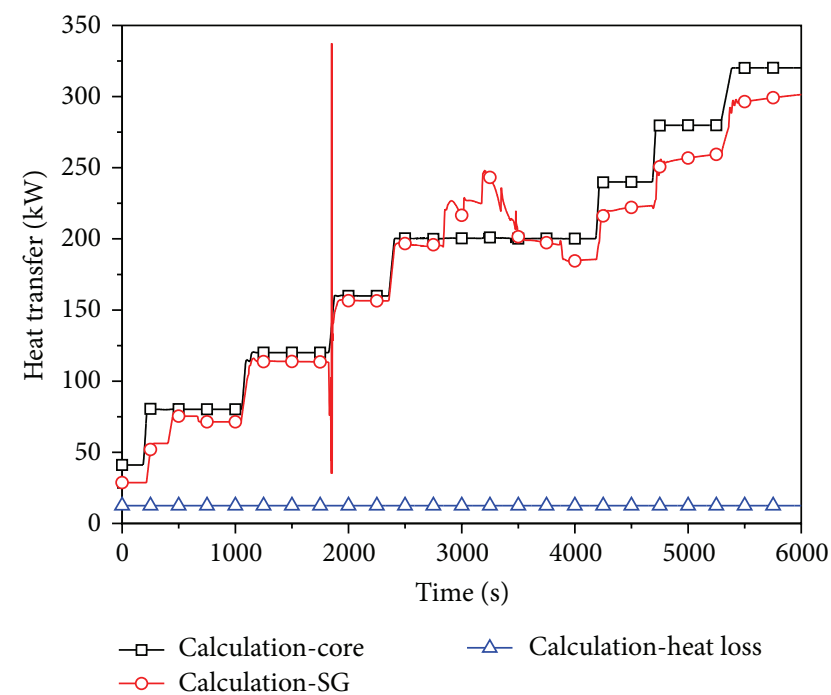

FIGURE 11: Various heat transfers at the primary system.

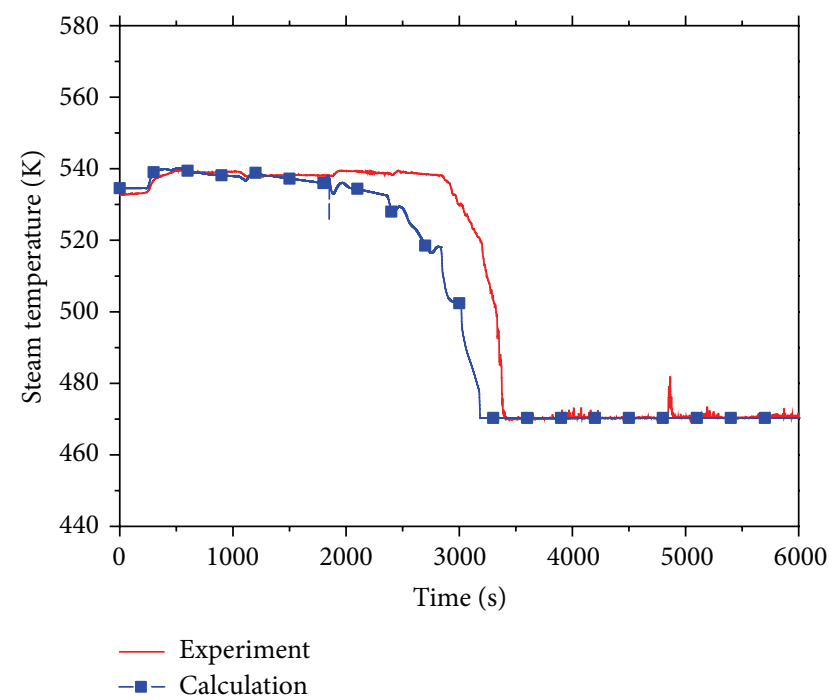

FIGURE 12: Steam temperature at the SG outlet. 
Considering the geometry of the integrated pressurized water reactor, the bypass heat transfer between the hot and cold sides in the pressure vessel is about $12 \%$ owing to its direct contact between the hot and cold sides through the hot leg riser wall. The code will be expanded to nonhomogeneous 5 equations to predict two phase conditions well.

\section{Nomenclature}

ADS: $\quad$ Automatic depressurization system

CPV: $\quad$ Cooling pool vessel

HEM: $\quad$ Homogeneous equilibrium model

HPC: $\quad$ High pressure containment

KAERI: Korea Atomic Energy Research Institute

MASLWR: Multiapplication small light water reactor

OSU: $\quad$ Oregon State University

PCS: $\quad$ Primary cooling system

PIRT: Phenomena identification and ranking table

PRHRS: Passive residual heat removal system

PWR: $\quad$ Pressurized water reactor

SG: $\quad$ Steam generator

SMART: System-integrated modular advanced reactor

TASS/SMR: Transient and setpoint simulation/system-integrated modular reactor.

\section{Conflict of Interests}

The authors declare that there is no conflict of interests regarding the publication of this paper.

\section{Acknowledgments}

This work was supported by the National Research Foundation of Korea (NRF) Grant funded by the Korea government (MSIP) (no. 2012M2A8A4025980), and the authors would like to acknowledge the International Atomic Energy Agency (IAEA) for supplying the experimental data for the code validation [12].

\section{References}

[1] IAEA, "Innovative small and medium sized reactors: design features, safety approaches and R\&D trends," IAEA-TECDOC 1451, IAEA, Vienna, Austria, 2005.

[2] K. K. Kim, W. Lee, S. Choi, H. R. Kim, and J. Ha, "SMART: the first licensed advanced integral reactor," Journal of Energy and Power Engineering, vol. 8, pp. 94-102, 2014.

[3] Y. J. Chung, I. S. Jun, S. H. Kim, S. H. Yang, H. R. Kim, and W. J. Lee, "Development and assessment of system analysis code, TASS/SMR for integral reactor, SMART," Nuclear Engineering and Design, vol. 244, pp. 52-60, 2012.

[4] R. B. Duffey and J. P. Sursock, "Natural circulation phenomena relevant to small breaks and transients," Nuclear Engineering and Design, vol. 102, no. 2, pp. 115-128, 1987.

[5] T. Watanabe, Y. Anoda, and M. Takano, "Stability of singlephase natural-circulation flows in steam generator U tubes," Annals of Nuclear Energy, vol. 60, pp. 344-349, 2013.
[6] A. F. Wibisono, Y. Ahn, W. C. Williams, Y. Addad, and J. I. Lee, "Studies of various single phase natural circulation systems for small and medium sized reactor design," Nuclear Engineering and Design, vol. 262, pp. 390-403, 2013.

[7] A. Mangal, V. Jain, and A. K. Nayak, "Capability of the RELAP5 code to simulate natural circulation behavior in test facilities," Progress in Nuclear Energy, vol. 61, pp. 1-16, 2012.

[8] N. T. Demick, M. R. Galvin, J. T. Groome, and B. G. Woods, "OSU MASLWR Test Facility Description Report," OSUMASLWR-07001, OSU, 2007.

[9] B. G. Woods and F. Mascari, Plan for an IAEA International Collaborative Standard Problem on Integral PWR Design Natural Circulation Flow Stability and Thermo-Hydraulic Coupling of Containment and Primary System During Accidents, OSU-ICSP09001, OSU, IAEA, 2009.

[10] B. Chexal, G. Lellouche, J. Horowitz, and J. Healzer, The ChexalLellouche Void Fraction Correlation for Generalized Applications, NSAC-139, EPRI, 1991.

[11] B. D. Chung, Development of a Phenomena Identification and Ranking Table of Thermal Hydraulic Phenomena for SMART, KAERI/TR-3780/2009, KAERI, 2009.

[12] IAEA, "Evaluation of advanced thermohydrulic system codes for design and safety analysis of integral type reactors," IAEATECDOC 17 33, IAEA, Vienna, Austria, 2014. 


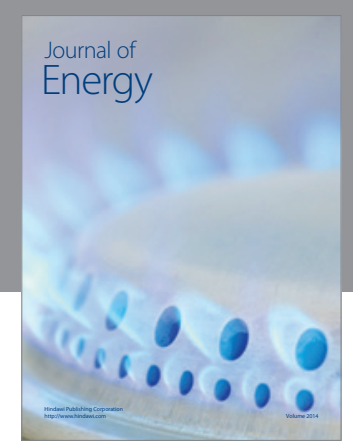

Journal of

Industrial Engineering
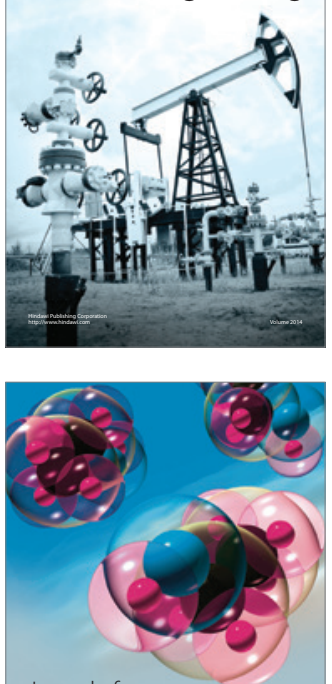

Fuels
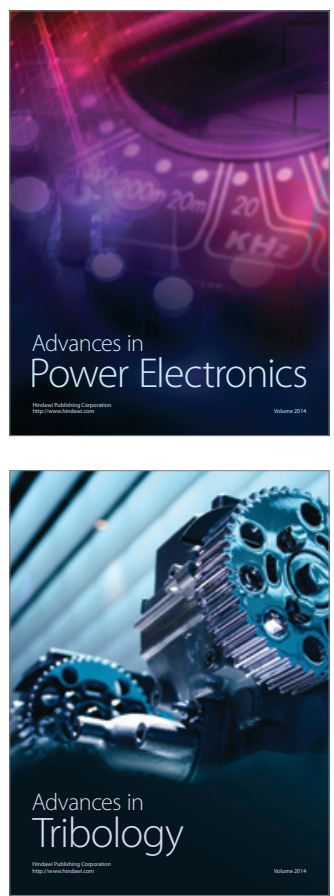

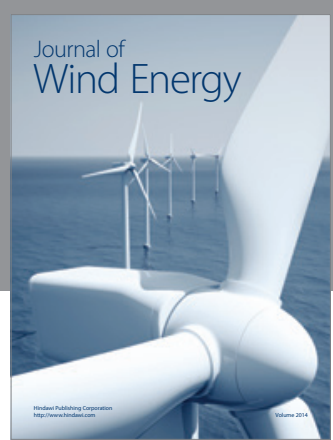

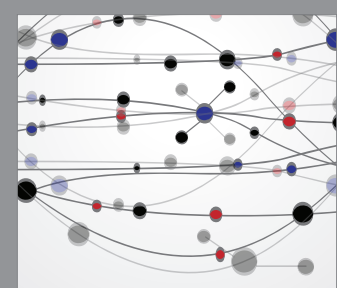

The Scientific World Journal

Submit your manuscripts at http://www.hindawi.com

Journal of

Structures
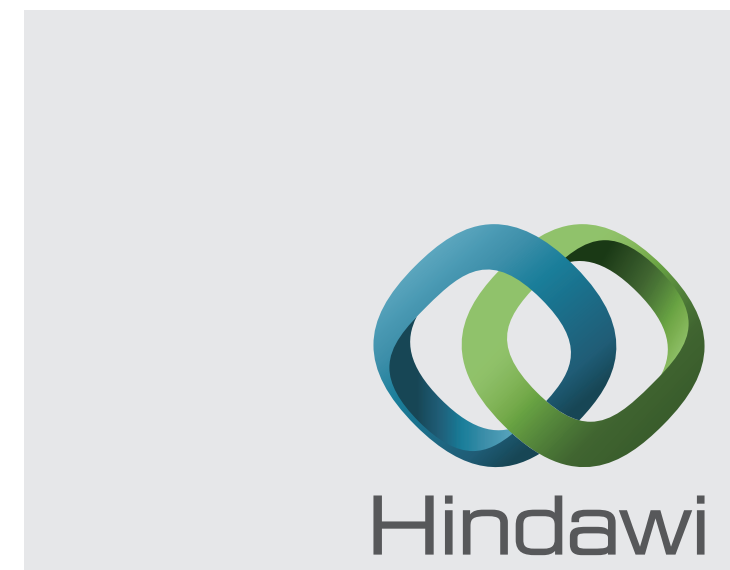

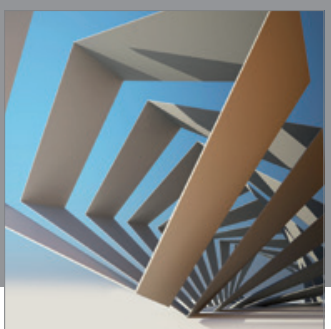

Rotating

Machinery
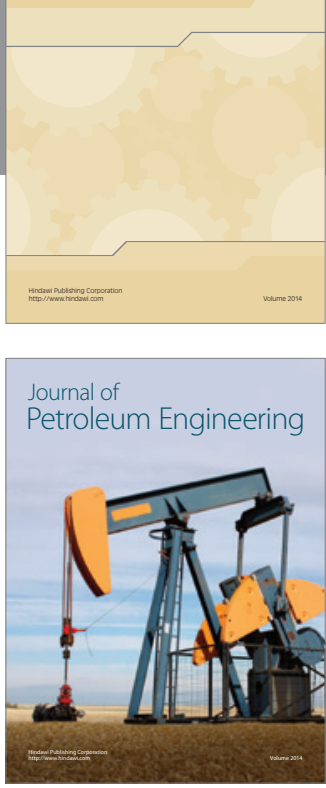

Journal of

Solar Energy
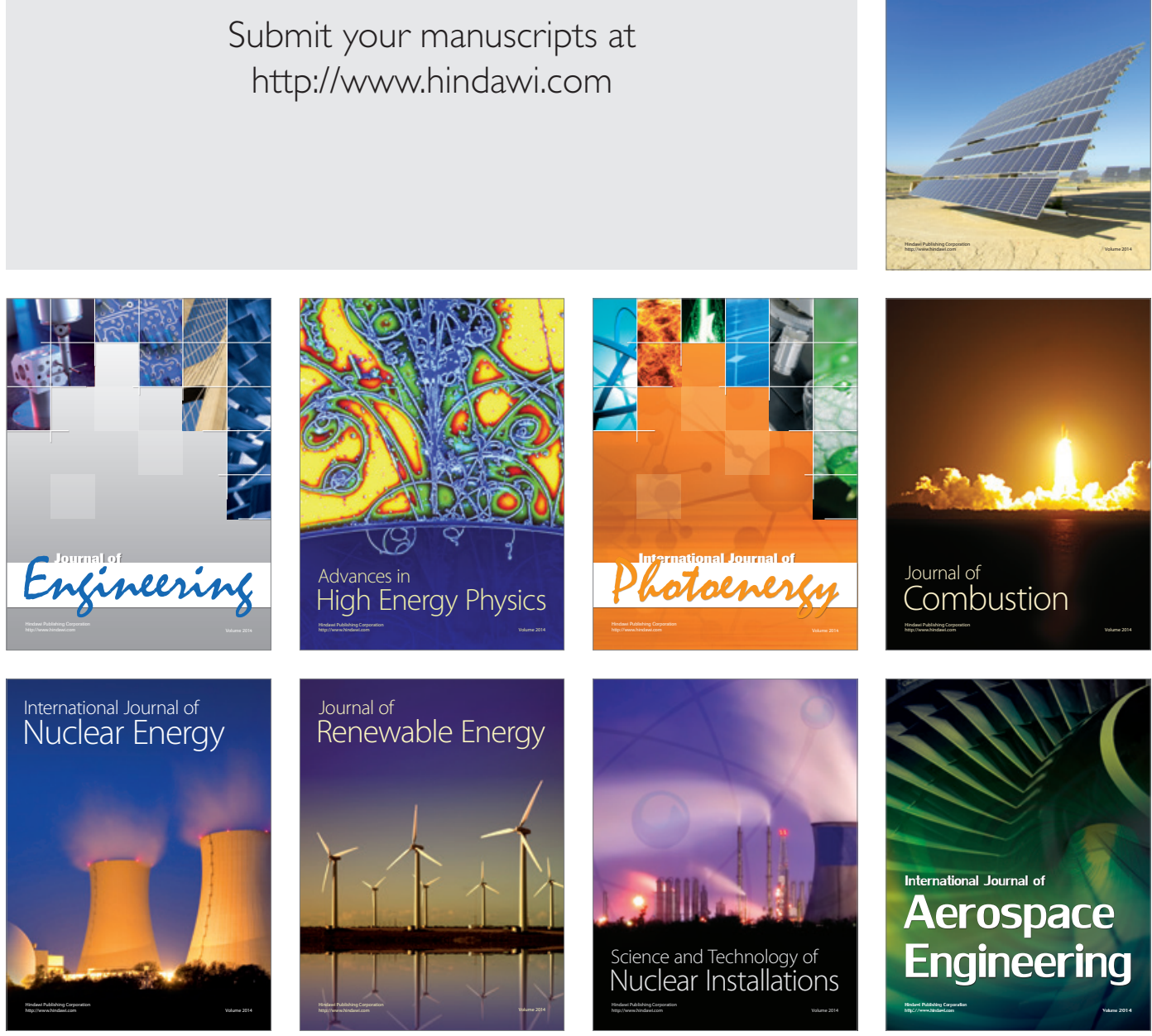